\title{
Waste Water Recycling in the Hospitality Industry
}

\author{
Ibrahim Adamu Sadi
}

\author{
Esther 0. Adebitan
}

\author{
Department of Hospitality and Tourism Management
}

The Federal Polytechnic Bauchi, Nigeria

\section{Doi:10.5901/ajis.2014.v3n7p87}

\begin{abstract}
Water is an indispensable but scarce natural resource, used in the hotel intensively for sanitary and food processing purposes, producing and letting out vast amount of wastewater in the process. Untreated waste water has detrimental effects on the environment and subsequently impacts negatively on human and other forms of life. This is aside from the fact that hotels constantly have to commit a lot of finances into obtaining fresh water from the mains to meet with huge water demands. Fortunately, water is a renewable resource which may be reclaimed for both economic and environmental benefits. Recycling wastewater therefore, makes it a resource rather than a waste. This study looked at how wastewater generated from hotels may be collected, treated and reused for other non portable purposes. A three star hotel situated within the Bauchi metropolis was used as case study with the objective of determining the volume of water used in the hotel on daily basis, find out how waste water from all the use-sources may be collected and treated using biological process and to explore how treated wastewater may be put to profitable use in the hotel. The study found out that the hotel uses an average of 72,142.7 litres daily. The system found suitable to be adopted by the hotel is the three chamber treatment system. It is recommended that hotels use treated wastewater to green the environment, nurture a mini vegetable garden, for car wash, laundry and for flushing toilets.
\end{abstract}

Keywords: Wastewater, Hotel, Recycling, Water Treatment

\section{Introduction}

Water, according to the Oxford Advanced Learners Dictionary (2005) is 'a liquid without colour, smell or taste that falls as rain, is in lakes, rivers and seas.' Water is used for drinking, washing, cooking and is essential to all forms of life. Water on the planet exists in many forms, which includes solid, liquid and gaseous.

Water, is assumed to be becoming scarce (Punmia, Jain and Jain, 2007). Water scarcity is a situation where there is insufficient water to satisfy normal requirement. Different degrees of water scarcity according to Winpenny (1997) include absolute, life threatening, seasonal, temporary, and cyclical. Scarcity often arises because of socio-economic trends having little to do with basic needs Water scarcity can be caused either by population growth, climatic change and variations, water demand, water quality and land use.

The scarcity of water necessitates the reuse of waste water not only for agricultural purposes, but also for nonpotable use domestically. According to Punmia, Jain and Ashok (2007), the reuse of liquid waste water generated from the industries and domestic sources for domestic and agricultural purposes has been occurring since historical times. Planned reuse has gained importance only two or three decades ago, as the demands for water dramatically increased. This was due to technological advancement, population growth, urbanization which put great stress on the natural water cycle.

\subsection{What is waste water}

According to Ichobanoglons, Burton and Stansel (2003) every community produces both liquid and solid waste and air emissions. The liquid waste is essentially the water supply of the community after it has been used in a variety of applications. Waste water is a term applied to any type of water that has been utilized in some capacity that negatively impacts the quality of the water and is no longer considered fit for human consumption.

Depending on their origin, wastewaters can be classed as sanitary, commercial, industrial or surface runoff.

i. Sanitary Sewage: Dispense water from residences and institutions carrying body wastes, ablution wastes, 
food preparation wastes, laundry wastes and other waste products of normal living, is classed as domestic or sanitary sewage.

ii. Commercial Wastes: Liquid-carried wastes from stores and service establishment serving the immediate community, termed commercial wastes are included in the sanitary or domestic sewage category if their characteristics are similar to household flows.

iii. Surface Run-Off: also known as storm flow or overland flow, is that portion of precipitation that runs rapidly over the ground surface to a defined channel.

Municipal wastewater contains a variety of inorganic substances from domestic and industrial sources. Pathogenic virus, bacteria, protozoa and helminthes may be present in raw municipal wastewater at certain levels and will survive in the environment for long periods, as pathogenic bacteria will be present in wastewater at much lower levels than the coliform group of bacteria, which are much easier to identify and enumerate. Escherichia coli are the most widely adapted indicator of faecal pollution and they can also be isolated and identified fairly simply with their numbers usually being given in the form of Faecal coliforms (Fc) $100 \mathrm{ml}$ of wastewater.

\subsubsection{Wastewater management}

There are three constituents and interrelated aspects of wastewater management. These are collection, treatment and disposal/reuse. The planning and design of wastewater collection facilities involves the determination of wastewater flow rates; the hydraulic design of sewers, large conduits and junction and diversion structures; the selection of sewer appurtenances and pumping stations (Punmia et al, 2007). With the modern development in other fields, many recent changes have been made in wastewater collection; notable amongst them being the photogrammetric and computer techniques to the design of sewers, the improvement of construction materials and the application of computers in the control of storm sewers.

\subsubsection{Treatment of Wastewater}

Treatment of wastewater is essential in order to reduce the spread of communicable disease caused by pathogenic organisms in the sewage and to prevent the pollution of surface and groundwater. The treatment of wastewater is carried out by a combination of physical unit operation and chemical and biological unit processes, before the end products can be safely disposed off. The form of treatment normally adopted consists of providing an environment in which natural processes of decay can be intensified and controlled so as to take place in the least objectionable manner as opined by Punmia et al (2007).

\subsubsection{Disposal/reuse of wastewater}

After treatment, the problems of disposal arise. The most important recent trend in the field of disposal is the establishment of increasingly stringent requirements to protect the environment. Currently used effluent disposal methods are:

i. Dilution in streams and rivers

ii. Land application and

iii. Reuse in aquaculture and crop irrigation.

The ideal wastewater management system consisting of collection, treatment and disposal/reuse should however satisfy

i. Health Criteria: The system should be so designed that pathogenic organisms do not spread. The treatment method chosen should be such that high degree of pathogen destruction is achieved and other harmful chemical pollutants are removed or neutralized to the largest extent possible.

ii. Reuse Criteria: The treatment processes used should be such that the treatment effluent is safe to be reused for aquaculture, agriculture, industrial cooling and ground recharge.

iii. Ecological Criteria: If the treated effluent is not re-used, but is disposed of in the receiving waste, its characteristics should be such that the aquatic environment is protected and the self-purification capacity of the recipient water is not exceeded. For this, a high degree of removal or organic matter (Bio Oxygen Demand) is required in order to prevent pollution of the receiving water course by oxygen depletion.

iv. Nuisance Criteria: The treatment system should be so designed that either it does not release objectionable 
odour or the degree of odour released must be below nuisance threshold. No part of the system should be aesthetically offensive.

v. Cultural Criteria: The methods chosen for collection, treatment, disposal and reuse should be such that they match with local habits, social customs and religious practices of the people of the area.

vi. Operational Criteria: The system should be such that it may operate with minimum difficulties, and greater degree of spill is not required. It should be such that operation is possible with locally available staff, with minimum possible training.

vii. Cost Criteria: The system should have minimum possible capital and running costs, which can be easily paid by the community. The return of the reuse of the end products is an important factor. If the end products are not reused, their disposal should be achieved with minimum possible cost.

\subsection{Wastewater as a resource}

Today in many regions of the world water has become a limiting factor, particularly for agricultural and industrial development. Water resources planners are continually looking for additional sources of water to supplement the limited resources available to their region. In such situations, sources substitution appears to be the most suitable alternative to satisfy less restrictive uses, thus allowing high quality waters to be used for domestic supply. In 1958, the United Nation Economic and Social Council provided a management policy to support this approach by stating that "no higher quality water unless there is a surplus of it, should be used for a purpose that can tolerate a lower grade" (UN, 1985).

\subsubsection{Types of wastewater reuse}

Water is a renewable resource within the hydrological cycle. The water recycled by natural systems provides a clean and safe resource which is then deteriorated by different levels of pollution depending on how, and to what extend it is used. Once used, however, water can be reclaimed and used again for different beneficial uses. The quality of the once-used water and the specific type of reuse define the levels of subsequent treatment needed, as well as the associated treatment process and costs (WHO, 1989).

1. Waste water reuse for agriculture and aquaculture

On a worldwide basis, wastewater is the most widely used low-quality water, particularly for agriculture and aquaculture. The fact that most farms in the developed countries find fresh waters too costly for agricultural purposes hence they opted for treated water liquid (wastewater).

2. Waste water reuse for Urban

In urban areas, reclaimed wastewater has been used mainly for non-potable applications as observed by Crook et al, (1992) such as:

i. Irrigation of public parks, recreation centres, athletic fields, school yards and playing fields, and edges and central reservations of highways.

ii. Irrigation of landscaped areas surrounding public, residential, commercial and industrial buildings.

iii. Irrigation of golf courses

iv. Ornamental landscapes and decorations water features, such as fountains, reflecting pools and waterfalls.

v. Fire protection.

vi. Toilet and urinal flushing in commercial and industrial buildings.

3. Waste water reuse for Industry

The most common uses of reclaimed water by industry are: evaporative cooling water, particularly for power stations, boiler-feed water, process water and irrigation of grounds surrounding the industrial plant.

The use of reclaimed wastewater by industry according to Biswas (1988) is a potentially large market in developed as well as in developing and rapidly industrializing countries. Industrial reuse is highly cost-effective for industries where the process does not require water for potable quality and where industries are located near urban centres where secondary effluent is readily available for reuse.

4. Waste water reuse for recreation and landscape enhancement

The use of reclaimed wastewater for recreation and landscape enhancement ranges from small fountains and landscaped areas to full water-based recreational sites for swimming, boating and fishing. As for other types of reuse, the quality of the reclaimed water for recreational uses should be determined by the degree of body contact estimated for each use in large impoundments, estimated for each use. In large impoundments, 
however, where aesthetic appearance is considered important it may be necessary to control nutrients to avoid eutrophication (Bartone, 1991).

\subsection{Wastewater treatment systems}

According to Punmia et al (2007), the wastewater treatment or sewage treatment is a broad term that applies to any process, operation or combinations of processes and operations that can reduce the objectionable properties of water carried waste and render it less dangerous and repulsive to man. Wastewater treatment consists of applying known technology to improve or upgrade the quality of a waste liquid (water). Usually, wastewater treatment will involve collecting the wastewater in a central segregated location (the wastewater treatment plant) and subjecting the wastewater to various treatment processes. Most often, since large volumes of wastewater are involved, treatment processes are carried out on continuously flowing wastewaters (continuous flow on "open systems) rather than as "batch" or a series of periodic treatment process in which treatment is carried out on parcels or "batches" of wastewaters.

While most wastewater treatment processes are continuous flow, certain operations, such as vacuum filtration, involving as it does storage of sludge, the addition of chemicals, filtration and removal or disposal of the treated sludge are routinely handled as periodic batch operations. Thus, the wastewater should be treated before its ultimate disposal in order to reduce the spread of communicable diseases caused by the pathogenic organisms in the sewage and prevent pollution of surface and groundwater.

Wastewater treatment, however, can also be organized or categorized by the nature of the treatment process operation being used such as physical (application of physical forces predominate. They consist of screening, mixing, flocculation, sedimentation, floating), chemical (chemical precipitation, gas transfer, adsorption, ion exchange, electrodialysis) or biological (activated sludge process, tricking filtration, sludge digestion). A complete treatment system may consist of the application of a number of physical, chemical and biological processes to the wastewater.

Conventional Treatment is the term used to describe the standard method of sewage treatment in

temperate climates. It comprises of the following stages of treatment:

i. Preliminary processes/treatment which consists of removing floating materials as well as heavy settleable inorganic solids; these also include pumping and flow measurement.

ii. Primary treatment aimed at the sedimentation of organic suspended solids, and

iii. Secondary (or biological) treatment in which biological processes are used to remove most of the organic matter.

Sometimes, the wastewater is also subjected to tertiary treatment (also known as advanced treatment) with the aim of removing the pollutants not removed in primary and secondary treatment. These pollutants may include soluble inorganic compounds (such as phosphorus and nitrogen) remaining organic material, pathogens, colloidal solids, soluble minerals and other toxic substances.

The most common treatment methods used in the tropics are trickling filters, septic tank filters, oxidation ponds, lagoons and chlorination.

\subsubsection{Advantages and Disadvantages of Recycling Waste Water}

Treated wastewater can be used in conserving the environment thus greening the environment and create an aesthetic environment for tourists and visitors alike to enjoy their stay in hotels, to flush toilets, water gardens and even to wash clothes (Bartone, 1991). By using wastewater as a resource rather than a waste product helps to reduce water bills, use less water resources, irrigate gardens during drought or water restrictions, cut down the amount of pollution going into the waterways, as well as help save money on new infrastructure for water provision and wastewater treatment.

The disadvantage of reusing wastewater however hinges on the financial cost of installing and maintaining a reuse system. Fresh water resources are becoming very scarce, for a sustainable water management, reclaimed water becomes a resource rather than a waste. The innovative technologies with multiple barriers have made it possible to augment the water supplies with reclaimed water by removing the contaminants.

\section{Research Problem Statement}

Fresh water is used intensively in the hospitality industry, especially in the hotel sub sector of the industry. Water is used in various sections of the hotel such as in the rooms, Food service/preparation areas, conference and banquet halls, special facilities, the laundry, conveniences, for gardening and from the swimming pools all these water become wasted 
after use. Water used in the hotels comes from the mains and at a cost which is enormous. According to Faechem, Bradley, Garelick, and Mara (1993), liquid waste water, if not treated or recycled properly, may bring about a hydrophic global warming, which in essence affect human life generally. it is observed however that economic and environmental benefits can also be gained if the waste water is harnessed and re-used. The research is therefore focused on exploring on how much more can be done in the hotel using recycled liquid waste water.

\section{Objective of Study}

This study is looking at how waste water generated from the kitchen, rooms, laundry, as conveniences and the swimming pools of hotels may be collected, treated and reused for other purposes useful to the hotel and its environment apart from potable use. A three star hotel situated in the Bauchi metropolis was used as a case study for the study with the following objectives;

1. Determine the volume of water used in the kitchen, rooms, laundry, conveniences and the swimming pools of the hotel on daily basis.

2. To find out how waste water from all the use-sources may be collected and treated using biological process.

3. To explore how treated waste water may be put to profitable use in the hotel.

\section{Result and Discussion}

The volume of water used in a particular unit will depend on the water saving potentials, which varies greatly at hotels depending on the type of facility and the occupancy rate of the hotel. Guest rooms are not the only area where water is being used, other areas include landscape irrigation, office and staff areas, food service/preparation conference and banquet, special facilities, laundry and others.

The above listed plan was used to calculate the volume of water used on daily basis in the hotel. The guest rooms have facilities that use water as toilets, urinals, shower heads or bath and faucets or wash hand basins. A male Water Closet (WC) uses approximately 6.1 Litre Per Flush (LPF), while the female WC uses 2 gallon per flush, the male urinals takes about 0.94 LPF. The Energy Policy Act of 1995 set maximum shower head flow rates at 2.5 gallon Per Minutes (GPM), the lavatory faucets can reasonably be reduced to $0.5 \mathrm{Gpm}$.

During the dry season, the hotel uses about $3000-5000$ litres of water for the purpose of irrigating its large landscaped area. The hotel has 3 bars, a kitchen, a restaurant, room service, banquet and night club where a lot of water is being used daily for cleaning, cooking and maintenance of some machines. Food is often heated in steamers using central boilers. The ice machines use about 5 gallons of water.

The preparation of food itself consumes a lot of water, ranging from the washing of ingredients to the main cooking and the final cooling. These processes are carried out using fresh water. The kitchen has a tank of 5000 litres which sometimes does not satisfy the daily water needs of the kitchen.

There are 4 offices in the hotel which have conveniences. it was observed that the toilets (female) flushes about 12 - 30 times daily while the urinals, flushes $4-20$ times and the faucets are being utilized $8-30$ times daily. The operation staff room has a 5000 litres tank which lasts for only two days.

The conference, banquets and restaurants conveniences water consumption were calculated using the same formula as with the toilets, urinals and faucets.

The swimming pools, spa and the cooling towers water utilized here are changed periodically for replacement. The swimming pool was a 2,800,000 litres capacity. The laundry is another area that uses a lot of water daily. It has a stationed 2000 litres tank of cold water and 500 litres tank of hot water for daily usage.

The hotel 100 staff drink from the fresh water and it is assumed that about 15\% of the staff do go off-duty daily. The total consumption per person was put at 1 litre per person which equals 75 litres consumed daily.

The formula for calculating water consumption in the hotel room is as follows:

$\mathrm{Q}=\mathrm{R} \times \mathrm{O}_{\mathrm{c}} \times \mathrm{L} \times \mathrm{W} \times \mathrm{P}$

Where:

$\begin{array}{ll}\mathrm{Q} & = \\ \mathrm{R} & = \\ \mathrm{O} & = \\ \mathrm{L} & = \\ \mathrm{W} & = \\ \mathrm{P} & =\end{array}$

The quantity of water used

Quantity of guest rooms

Average occupancy percentage of the hotel

Average laundry per room, hotels and sheets measured in pounds

Water used per pound of landing (water efficiency of washer)

Participation rate by guest and staff (percentage) 


\subsection{Research limitations}

The above formula is used worldwide in hotels to calculate water saving and water consumption on daily basis, but this cannot suffice for the hotel used for case study due to lack of accurate measurement of water collected from mains. Most of the hotel water saving facilities are leaking and some pipes are broken, resulting in a lot of water being wasted on the way.

\subsection{Computation of Water Consumption Volume in the case study hotel}

As at the time of this report, the hotel room occupancy which is the machinery for the calculation of water consumption stands at $37 \%$ average per night, therefore $37 \%$ was used to calculate the water consumption for the hotel. All the rooms and staff and guest or public conveniences use the male WC.

The volume of water used by the hotel on daily basis therefore:

$$
\begin{array}{lll}
\therefore W C=\quad \frac{37 \times 184}{100}=68.08 \text { (rooms) } & \\
\therefore 68.08 \times 6.1 \mathrm{LPF} & = & 415.288 \text { litres daily } \\
415.288 \times 4 \text { times daily } \quad= & 1661.152 \text { litres } \\
\text { Urinals which are found in public conveniences and staff areas }
\end{array}
$$

$\therefore 13$ urinals $\mathrm{x} 12$ times daily $\quad=\quad 156$ litres daily

Shower head in all the rooms and staff areas are the same

$\begin{array}{lll}\therefore \text { Rooms } & = & \frac{37 \times 184}{100}=68.08 \\ \therefore 68.08 \times 2.5 \text { glns } & = & 170.2 \times 4 \\ 6808 \times 4 \text { times } & = & 2,723.20\end{array}$

WC public areas (male and female) and staff areas

20WC $\times 8$ times flush daily $=160$ litres daily

Faucets (rooms) $\quad \frac{37 \times 184}{100}=68.08$

$\therefore 68.08 \times 0.5$ gallon $=34.04$ gallons $\times$ litres

$136.1 \times 4$ times $=\quad 544.64$ litres

Faucets (public areas) $\frac{37 \times 184}{100}=68.08$

$\therefore 22 \times 0.5$ gallon $\quad=\quad 11$ gallons $\times 4$ litres $=44$

$44 \times 4$ times $=20$ litres $\times 2$ times $=40$ litres

Ice Machine to Capacity

5 gallon $\times 4$ times $\quad=\quad 20$ litres $\times 2$ times $\quad=\quad 40$ litres daily

4 gallons $\times 4$ litres $=16$ litres $\times 6 \times 15=4,000$ litres daily on the

average

Food preparation and the kitchen and service processes

7,000 litres daily on the average

Laundry services (manual) = $\quad=3,000$ litres daily

Laundry services (machines) $\quad=\quad 1,5000$ litres on the average daily

Staff intake $\quad=\quad 75$ litres on the average daily

Swimming pool - $\quad$ This is changed within the period of two (2) months

$$
=\quad 2,800,000 \div 60 \text { days }=\quad 46,666.67 \text { litres daily }
$$

Others This will include other water usage like ablution, washing of engines, cooling that are not mentioned.

$$
=\quad 3,000 \text { litres daily }
$$

Going by the above computation of the water consumptions of sections in the hotel therefore, the following estimations are arrived at as follows:

- WC

- Urinals

$=\quad 1,821.152$ litres daily

- Shower head

$=\quad 156$ litres daily

- Faucets

- Ice machine

$=\quad 2,723.20$ litres daily

$=\quad 720.64$ litres daily

$=\quad 40$ litres daily 


$\begin{array}{lll}\text { - } & \text { Pre-rinsed } \\ \text { - } & = \\ \text { - } & \text { Food prigation } \\ \text { - } & \text { Laundry services } & = \\ \text { - } & \text { Staff in take } \\ \text { - } & \text { Swimming pool } \\ \text { - } & = \\ & \text { Others } \\ & \text { Total Average }\end{array}$

\author{
1,440 litres daily \\ 4,000 litres daily \\ 7,000 litres daily \\ 4,500 litres daily \\ 75 litres daily \\ 46,666.67 litres daily \\ 3,000 litres daily \\ 72,142.7 litres daily Water Consumption
}

\subsection{Suitable method for collecting and treating liquid waste in the hotel}

The case study hotel uses the combined or central collection system According to Punmia et al (2007), the best method of collecting liquid waste is the unit system, where every section has its collection centre, that is, the kitchen has its collection centre, the laundry has its collection centre, the rooms have their collection centre, the staff dressing rooms and likewise all other units should have their own separate collection centres. This is done in other to avoid contamination of the wastewater by some chemical components that are not needed from a particular unit of discharge.

This system is found not to be suitable for the case study hotel and indeed hotels in Nigeria generally. This is because of intermittent power outages being experienced in the country, which may cause a failure and ineffectiveness of the method.

The system found suitable to be adopted by the hotel is the three chamber treatment system. It is a secondary type of treatment in which after treatment the water may be put to many uses with exception of potable use (drinking).

A waste water treatment system model was developed for the case study hotel as shown on Figure 1. The waste water is to be collected from the different units in the hotel to the central collection centre. It will pass through the aeration chambers to the final liquid waste chamber. The liquid waste now goes into the treatment chambers. The first chamber will be carrying a rough plastic or rock medium. The sewage will slowly move through the porous bed and the effluent will be collected at the bottom. These porous materials become coated with a dense slimy bacteria growth which provides a home for a heterogeneous microbial community which includes bacteria, fungi and protozoa as well as other organisms that exists in water. As the sewages drains through the porous bed, this microbial community will absorb and break down the dissolved organic nutrients in the sewage; this reduces the Biochemical Oxygen Demand (BOD).

Aeration of the sewage will occur by the movement of air through the porous bed. The sewage may need a recirculation of air several times through the filter in order to reduce the BOD sufficiently. These excess amounts of nutrients produce an excessive amount of slime on the medium which in turn will reduce aeration, leading to the need to renew the porous bed.

From there, it moves into the second chamber where contaminant removal, known as "biotransformation" will take place. Traditionally, the organic matter in wastewater is measured in five days biochemical oxygen demand (BOD5). The rocks that coated in slime which is continuously removed or sloughed off will occur in all the stages and therefore should be renewed at intervals. The sloughed of material should be discharged in the effluent.

The last stage or the chamber is to perfectly remove the smell and other bacteria and microorganisms that escaped the two stages of treatment. The clean water will then go into a clean chamber where it will be accommodated for disposal to the gardens, for car wash, and for other utilization. 


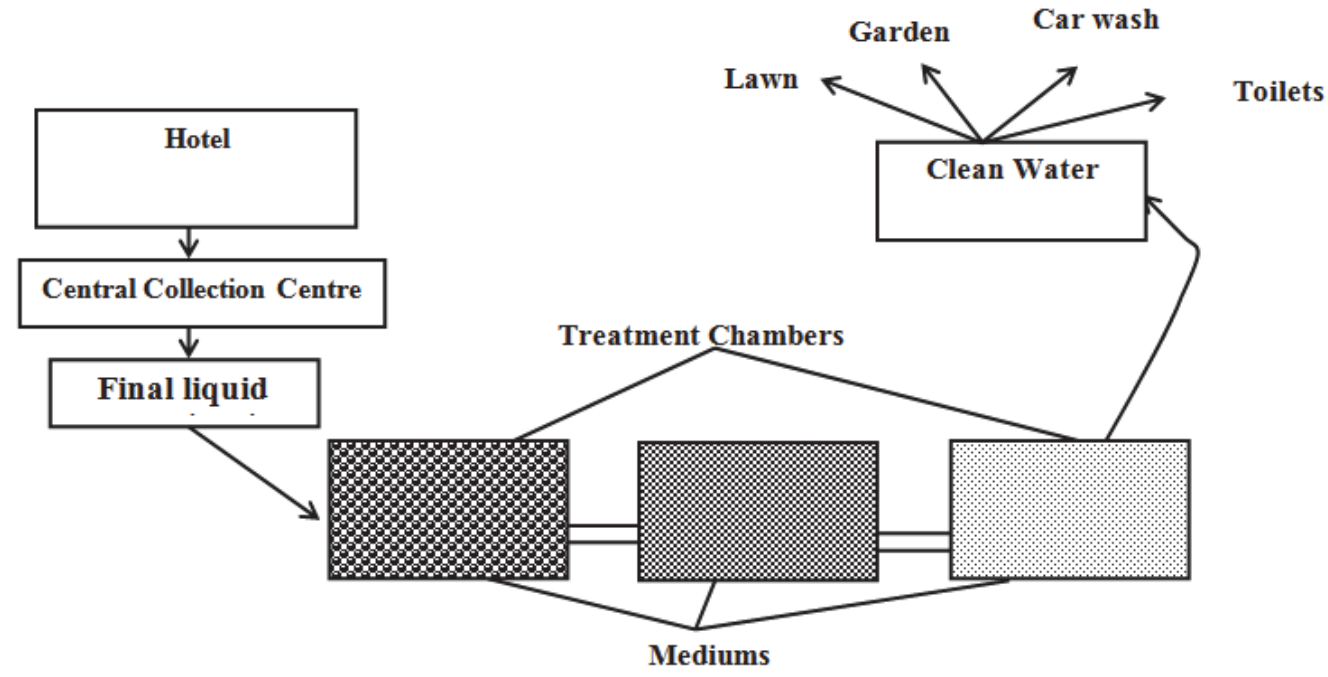

Figure 1: Hotel wastewater treatment system model.

Source: Researchers

\subsection{Ways recycled wastewater may be put to profitable use in a hotel}

Treated water is most commonly used for non-potable (not for drinking) purposes. Recycled water can satisfy most water demands, as long as it is adequately treated to ensure water quality appropriate for use. Hotels may use the treated water to green the environment, nurture a mini vegetable garden for the hotel use, for car wash laundry and for flushing toilets. The hotel can also establish a mini golf course and field watered with the treated water. The treated water may also be used to irrigate and landscape the environment. The treated water is useful for fire protection and air conditioning.

\section{Conclusion and Recommendations}

The incorporation of wastewater recycling into hotels policies is important. Wastewater reuse may help reduce costs of using fresh water. The use of wastewater has been practiced in many parts of the world for centuries. Based on the findings of this research, the following recommendations are made;

1. That hotels managers/proprietor should consider recycling wastewater from their hotels for the many benefits which include economic and environmental benefits.

2. That the Hospitality and Tourism Management Association of Nigeria, in collaboration with Hotel Owners Association should include in their plan, all hotels that are coming up or being constructed should have a liquid waste (wastewater) treatment plant in the initial plan of the hotel building. And

3. That the government should direct the National Association of Builders and Architectures to include or prioritize the inclusion of wastewater plant into all building which have a certain standards or number of rooms.

\section{References}

Bartone, C.R. (1991). International Perspective on Water Resources Management and Wastewater Use-Appropriate Technnologies. Water Science Technology; 23, 2039 - 2047.

Biswas, A.K. (1988). Role of Wastewater Reuse in Water Planning and Management. In: AK Biswas and A. Arar (Eds) Treatment and Reuse of Waste Water. London Butterworths

Crook, J., Amernmman, D.K., Okun, D.A. and Mathews, R.L. (1992). Guidelines for Water Reuse. Cam Dresses and Mckee, Inc. Cambridge Massachusetts.

Faechem, R.G. Bradley, D.J.; Garelick, H. and Mara, D.D. (1993). Sanitation and Disease: Health Aspects of Excreta and Wastewater Management. John Wiley Chichester.

Hespanhol, I. and Prost, A. (1994). WHO guidelines and National Standards for Reuse and Water Quality. Water Res., 28(1) 119 - 124.

Hillman, P.J. (1988). Health Aspects of Reuse of Treated Wastewater for irrigation. Cited in. Pescod, M.B and Arar, A. (Eds) Ch. 5, Treatment and Use of Sewage Effluent for Irrigation.. Butterworths, Sevenaks, Kent.

Ichobaoglous, G.; Burton, F.L., Stensel, H.D; . (2003) Wastewater Engineering, Treatment and Reuse Metcalf and Eddy Tata McGraw 
Hill Publishing Company Limited. New Delhi India.

Kandiah, A. (1994). The Use of Wastewater in Irrigation. Paper Presented at the WHO/FAO/UNCHS/UNEP Workshop on Health, Agriculture and Environment Aspects of the Use of Wastewater, Harare, Zimbabwe, 31 October to 4 November, 1994, WHO Geneva.

Punmia, B.C.; Jain, A. K and Ashok, K. (2007). Environmental Engineering - 2 Wastewater Engineering (Including Air Pollution) Laxmi Publications (D) Ltd New Delhi Madras Jalandhar Hyderabad.

Shande, G.B. (1985). Status of Wastewater Treatment and Agricultural Reuse with Special Reference to Indian Experience and Research and Development Needs. In: M.B. Pescod and A. Arar (Eds) Proceedings of the FAO Regional Seminar on the Treatment and Use of Sewage Effluent for Irrigation. Nicosia, Cyprus, 7 - 9 October, Butter Worth London.

Shuval, H.I; Adin, A; Fatal, B; Rawitz, E; and Yekutiel, P. (1986). Wastewater irrigation in Developing Countries - Health Effects and Technical Solutions. World Bank Technical Solutions. World Bank Technical Paper. No. 51, World Bank Washington D.C.

UN Department of Technical Corporation for Development (1985). The Use of Non-Conventional Waste Resources in Developing Countries. Natural Water Resources Series No. 14 United Nations DTCD, New York.

Winpenny, J.T. (1997). Managing Water Scarcity for Water Security. A Discussion Paper Prepared for the First FAO E-mail Conference on Managing Water Scarcity, 4 March to 9 April 1997. 